\title{
BMJ Open Psychological distress following a motor vehicle crash: evidence from a statewide retrospective study examining settlement times and costs of compensation claims
}

\author{
Rebecca Guest, Yvonne Tran, Bamini Gopinath, Ian D Cameron, Ashley Craig
}

To cite: Guest R, Tran $\mathrm{Y}$, Gopinath B, et al. Psychological distress following a motor vehicle crash: evidence from a statewide retrospective study examining settlement times and costs of compensation claims. BMJ Open

2017;7:e017515. doi:10.1136/ bmjopen-2017-017515

- Prepublication history and additional material are available. To view these files please visit the journal online (http://dx.doi org/10.1136//bmjopen-2017017515).

Received 27 April 2017 Revised 15 June 2017 Accepted 23 June 2017

CrossMark

John Walsh Centre for Rehabilitation Research, Kolling Institute for Medical Research, Sydney Medical SchoolNorthern, The University of Sydney, Sydney, Australia

Correspondence to

Rebecca Guest;

rebecca.guest@sydney.edu.au

\section{ABSTRACT}

Objective To determine whether psychological distress associated with musculoskeletal injuries sustained in a motor vehicle crash (MVC), regardless of time of onset, impacts compensation outcomes such as claim settlement times and costs. Second, to identify factors routinely collected by insurance companies that contribute to psychological distress during the compensation process.

Design Statewide retrospective study.

Data source Analysis of the New South Wales statewide (Australia) injury register for MVC survivors who lodged a compensation claim from 2011 to 2013.

Participants 6341 adults who sustained a musculoskeletal injury and who settled a claim for injury after an MVC. Participants included those diagnosed with psychological distress $(n=607)$ versus those not $(\mathrm{n}=5734)$.

Main outcome measures Time to settlement and total costs of claims, as well as socio-demographic and injury characteristics that may contribute to elevated psychological distress, such as socio-economic disadvantage, and injury severity.

Results Psychological distress in those with a musculoskeletal injury was associated with significantly longer settlement times (an additional 17 weeks) and considerably higher costs (an additional \$A41 575.00 or 4.3 times more expensive). Multivariate logistic regression analysis identified risk factors for psychological distress including being female, social disadvantage, unemployment prior to the claim, not being at fault in the MVC, requiring ambulance transportation and rehabilitation as part of recovery.

Conclusions Results provide compelling evidence that psychological distress has an adverse impact on people with musculoskeletal injury as they progress through compensation. Findings suggest that additional resources should be directed toward claimants who are at risk (eg, the socially disadvantaged or those unemployed prior to the claim), the major aim being to reduce risk of psychological distress, such as post-traumatic stress disorder, and associated risk of increased settlement times and claim costs. Prospective studies are now required that investigate treatment strategies for those at risk of psychological distress associated with an MVC.
Strengths and limitations of this study

- This is the first study to investigate the impact of psychological distress in all claimants experiencing a musculoskeletal injury and who lodge and settle their compensation claim for a motor vehicle crash (MVC) over a 2-year period in the state of New South Wales. It was revealed that the presence of psychological distress greatly increased settlement times and costs.

- The study identified risk factors associated with an increased likelihood of psychological distress after an MVC.

- The study has the potential to change medical practice and insurance policy for those at risk of psychological distress following an MVC.

- It was not possible to determine whether psychological distress was present prior to the MVC, as this information is not routinely collected by insurance companies.

\section{INTRODUCTION}

Motor vehicle crashes (MVCs) remain a major source of physical injury and distress. For example, in the UK, there were 194477 reported casualties in a traffic accident in 2014, ${ }^{1}$ while in Australia in 2013, the rate of annual hospitalised injuries associated with an MVC was 151.7 per $100000 .^{2}$ Psychological distress associated with an MVC has been shown to be substantial and prevalent. ${ }^{3-7} \mathrm{~A}$ recent meta-analysis investigated the extent of psychological distress associated with an MVC. ${ }^{3}$ Regardless of whether the psychological distress occurred prior to or after the MVC, the study revealed that traumatic brain injury, spinal cord injury and musculoskeletal injury (ie, whiplash) resulted in significantly elevated levels of distress ${ }^{3}$ and psychological distress has been shown to remain elevated for at least 3 years post-MVC. ${ }^{3-10}$ Recent prospective research found that one in two 
persons suffered elevated rates of psychological distress (eg, depression) soon after the MVC and many of these continue to experience elevated distress 12 months after the MVC. ${ }^{9}$ Factors such as more severe physical injury, older age and past negative emotional reactions to distress were associated with elevated psychological distress 12 months post-MVC. ${ }^{9}$ For the purpose of this study, psychological distress is defined as an unpleasant mental condition perceived as disturbing and which can impede daily functioning, with mental symptoms including agitation, fatigue, confusion, loss of motivation and depressed mood.

Research suggests the compensation process following an MVC increases distress; for example, health outcomes of people who lodge injury-related compensation claims are more likely to have higher levels of distress than those who do not claim. ${ }^{11-17}$ Furthermore, preliminary research suggests that when a person has experienced a physical injury as well as psychological distress, the cost of their claim has been shown to double. ${ }^{18}$ Other research has found poorer outcomes for claimants who were not at fault compared with those at fault. ${ }^{19}$ The potential negative impact of psychological distress in the claims process is clearly undesirable in terms of complicating medical treatment for the injured person and challenging policy direction and effectiveness for insurers. A more desirable outcome is to minimise time spent in the compensation process because this would likely reduce the negative impact on the individual's health and contain claim costs for healthcare systems and insurers. ${ }^{20}$

Musculoskeletal injuries are common following an MVC and often lead to compensation claims, ${ }^{21-23}$ and the risk of developing psychological distress with this physical injury is high. ${ }^{324}$ Musculoskeletal injuries typically involve soft tissue injuries to the lower back, shoulders, hips and knees as well as whiplash injuries and account for more than 65000 injuries in Australia each year following an MVC, at a cost in excess of $\$$ A950 million. ${ }^{25}$ Barriers to recovery from MVC-related musculoskeletal injuries include high initial pain intensity, ${ }^{26}{ }^{27}$ being female, ${ }^{20}{ }^{28}$ involvement in the compensation claims process ${ }^{1420}$ and elevated psychological distress. ${ }^{29}{ }^{30}$ Furthermore, recent research found significantly increased levels of psychological distress for MVC-related whiplash-associated disorder compared with controls. ${ }^{331}$

A review of research that focused on disability arising from an MVC concluded that there was a need to clarify rates of disability arising from an MVC, especially with regard to methodological issues and complicating factors like compensation. ${ }^{32}$ This is also true for the impact of psychological distress following an MVC, including the influence of involvement in compensation claims. ${ }^{3} 9$ Research in this area has been limited by uncertain diagnoses of psychological distress disorders and small sample sizes. In contrast, the research presented in this paper has addressed many of the limitations of prior research. For instance, it used a database of 6341 persons with musculoskeletal injury from the statewide injury register of the New South Wales (NSW) State Insurance Regulatory Authority (SIRA), the authority that administers the NSW Compulsory Third Party (CTP) scheme. This statewide register also provides records with confirmed diagnoses of psychological distress, based on the International Statistical Classification of Disease and Related Health Problems, Tenth Revision, Australian Modification (ICD-10-AM) ${ }^{33}$ regardless of when the psychological distress was first diagnosed. The NSW CTP scheme is a fault-based scheme with limited access to entitlements for those at fault. Its purpose is to compensate those with injuries who were not at fault in the MVC with the claim requiring police and medical reports as evidence, in addition to a personal injury claim form. ${ }^{34}$ An estimated $55 \%$ of all NSW MVC-related injuries result in the lodgement of a CTP claim. ${ }^{35}$

The objective of this research was to analyse the data of all NSW MVC survivors who sustained a musculoskeletal injury and who settled their claim over a 2-year period. Compensation outcomes of those without diagnosed psychological distress were then compared with those with diagnosed psychological distress. Specifically, the aim was to determine the impact of psychological distress, regardless of time of onset, on claim settlement times and total costs. ${ }^{34} \mathrm{~A}$ further aim was to determine factors, routinely collected by NSW CTP insurance companies and collated by SIRA, that predict elevated risk of having psychological distress. Accordingly, findings should address two key research questions: (1) whether psychological distress is associated with longer claim time to completion and greater claim costs and (2) what injury or demographic characteristics are associated with psychological distress. The findings should be beneficial for informing general practitioners and insurer policymakers and thus improve healthcare practices for injury-related compensation claimants.

\section{METHOD}

\section{Participants}

Permission was sought and granted on 22 November 2016 from SIRA to access a total of 24164 claims from the Personal Injury Register (PIR) of SIRA to determine their potential inclusion in the analysis. The PIR contains all MVC-related claims that occur in NSW. Inclusion criteria consisted of (i) the injured adult (18+) having a musculoskeletal injury and (ii) the claim had been lodged and also settled over a 27-month period (October 2011December 2013). Claims that had been lodged but not settled and claims involving catastrophic injuries such as spinal cord injury and severe traumatic brain injury were excluded (catastrophic-injury-related claims are directed toward an alternative scheme in NSW). This resulted in 6341 participants who had experienced an MVC and sustained a musculoskeletal injury and who lodged and settled a claim in NSW, Australia, between October 2011 and December 2013 (27 months). The combined cohort data were received from SIRA in de-identified form, and 
therefore, human research ethics approval was deemed not to be required.

\section{Measurements}

Musculoskeletal injury severity was assessed using the New Injury Severity Score, which computes the simple sum of squares of the three most severe injuries identified by the Abbreviated Injury Scale. ${ }^{36}$ The Index of Relative Socioeconomic Disadvantage was calculated from the Socio Economic Index for Areas (SEIFA), which ranks areas in Australia according to relative socio-economic advantage and disadvantage. ${ }^{37}$ Rehabilitation indicator refers to whether the claimant required rehabilitation as part of their recovery plan. Presence of psychological distress, such as post-traumatic stress disorder (PTSD) or major depressive disorders, was determined using the ICD-10-AM Classification of Mental and Behavioural Disorders: Clinical Descriptions and Diagnostic Guide$\operatorname{lines}^{38}$ at some time within the claims process (the database is progressively updated over the duration of the claim). Psychological distress was determined from sources such as reports and independent assessments from general practitioners, psychiatrists and psychologists. It is recognised that psychological distress could be present prior to the claimant's MVC and that this has the potential to influence psychological distress post-MVC. ${ }^{3}$ However, timing of onset of psychological distress was not the aim of this research given that such information is not routinely collected by NSW insurance companies and is therefore not collated by the NSW regulatory authority. Of the 6341, those with musculoskeletal injury without psychological distress numbered 5374 (90.4\%) and those with both musculoskeletal injury and psychological distress numbered 607 (9.6\%).

\section{Statistical analysis}

A retrospective design was employed to analyse the PIR datasets of all NSW MVC survivors at the time of their claim lodgement (both minor claims, that is, 'Accident Notifications Forms' and full claims) over 27 months, and who met the inclusion criteria. Reporting was guided by the relevant checklist (see STROBE Statement in supplementary file 1). Descriptive statistics were used to summarise demographic and claim/accident characteristics of the participants by psychological distress status. The differences in the demographics and claim characteristics between those that claimed compensation and those that did not were compared using analysis of variance (ANOVA) tests for continuous variables and $\chi^{2}$ tests for categorical variables. In order to determine predictive factors, logistic regression was employed. Only statistically significant socio-demographic and injury variables from table 1 were included in the logistic regression analysis from which unadjusted ORs were determined. Following this, all the variables were again used in backward elimination $(p<0.05)$ logistic regression, and adjusted ORs were calculated.
Logistic regression can provide information on factors that are associated with having psychological distress, and advantages of employing this statistical methodology include its ability for isolating predictors and for producing ORs. ${ }^{39}$ In order to determine predictive factors, logistic regression was employed. Potential predictor variables from the socio-demographic and injury variables from table 1 were considered and significant variables were retained for the logistic regression analysis. Univariate analysis on the significant variables was conducted from which the unadjusted ORs were determined. Following this, variables for the final model were selected using a backward elimination technique based on changes in likelihood ratios. Significant variables $(\mathrm{p}<0.05)$ from the logistic regression were used in the final model and adjusted ORs were calculated. While table 1 showed that there was a significantly higher probability $(\mathrm{p}<0.01)$ for those who had psychological distress also having legal representation $(61.0 \%)$ compared with musculoskeletal-injury-only claimants $(18.9 \%)$, this injury characteristic was excluded from the logistic regression as legal representation can be instigated not only at the time of the claim lodgement, but at any time throughout the claims process, thus making it difficult to establish its predictive association with psychological distress. Again, it should be noted that psychological distress can develop before the injury, as well as at any time throughout the claims process.

All variables selected for the logistic regression have been investigated in prior studies for their relevance to injury outcomes following MVC. ${ }^{11}{ }^{40}$ To determine the predictive capacity of the logistic regression model, receiver operating characteristics (ROC) estimates were calculated. The ROC plots the true-positive rate (sensitivity) against the false-positive rate (1-specificity) in detecting factors that influence greater time to claim settlement and elevated costs for MVC claimants with musculoskeletal injuries with and without psychological distress.

\section{RESULTS}

Socio-demographic and injury characteristics are shown in table 1 . All factors shown in table 1 were either preinjury factors or assessed at the time of lodging the claim, except for legal representation, which can potentially occur at any time during the claims process. Mean days from MVC to lodgement of a minor 'no fault' claim (Accident Notification Form) was 23 days $(\mathrm{SD}=22.8)$ and to full claim lodgement was 110 days $(\mathrm{SD}=84.0)$.

Table 2 shows a breakdown of musculoskeletal injury types for the sample separated by musculoskeletal injury only compared with musculoskeletal injury+psychological distress. While it is accepted that an MVC survivor is vulnerable to sustaining several different categories of injuries (eg, whiplash and lumbar and other soft tissue injuries), Table 2 shows that the most common musculoskeletal injury was soft tissue, followed by whiplash injuries. 
Open Access

Table 1 Socio-demographic and injury characteristics of NSW MVC claimants 2011-2013

\begin{tabular}{|c|c|c|c|}
\hline & Musculoskeletal injury & $\begin{array}{l}\text { Musculoskeletal } \\
\text { injury+psych distress }\end{array}$ & \\
\hline Variable & $(n=5734)$ & $(\mathrm{n}=607)$ & $\mathbf{p}$ \\
\hline Age (years), mean (SD) & $42.8(16.3)$ & $44.4(15.9)$ & 0.02 \\
\hline New Injury Severity Score, n (\%) & & & 0.02 \\
\hline Minor-moderate 1-8 & $5259(91.9)$ & $539(88.8)$ & \\
\hline Serious $9-15$ & $348(6.1)$ & $54(8.9)$ & \\
\hline Severe-critical $16-75$ & $114(2.0)$ & $14(2.3)$ & \\
\hline Index of Relative Socioeconomic Disadvantage, mean (SD) & $1017.0(86.4)$ & $986.5(89.2)$ & $<0.01$ \\
\hline Index of Relative Socioeconomic Disadvantage, n (\%) & & & $<0.01$ \\
\hline Most disadvantaged & $983(17.4)$ & $182(30.3)$ & \\
\hline Disadvantaged & $803(14.2)$ & $72(12.5)$ & \\
\hline Average & $1007(17.8)$ & $113(18.8)$ & \\
\hline Advantaged & $853(15.1)$ & $95(15.8)$ & \\
\hline Most advantaged & $1996(35.4)$ & $136(22.6)$ & \\
\hline Male, n (\%) & 2417 (42.2) & $212(34.9)$ & $<0.01$ \\
\hline Employment status, $\mathrm{n}(\%)$ (yes) & 4197 (73.2) & $364(60.0)$ & $<0.01$ \\
\hline Occupation skill level, n (\%) & & & $<0.01$ \\
\hline Managers and administrators & $567(9.9)$ & $34(5.6)$ & \\
\hline Professionals & $1026(17.9)$ & $34(5.6)$ & \\
\hline Para-professionals & $213(3.7)$ & $74(12.2)$ & \\
\hline Tradespersons & $257(4.5)$ & $17(12.2)$ & \\
\hline Clerks & $600(10.5)$ & $26(4.3)$ & \\
\hline Sales persons and personal service workers & $680(11.9)$ & $63(10.4)$ & \\
\hline Plant and machine operators and drivers & $225(3.9)$ & $64(10.5)$ & \\
\hline Labourers and related workers & $537(9.4)$ & $22(3.6)$ & \\
\hline At fault* (no), n (\%) & $4866(87.9)$ & $568(96.1)$ & $<0.01$ \\
\hline Prior claim (yes), n (\%) & $620(10.8)$ & $86(14.2)$ & 0.012 \\
\hline Economic loss claim (no), n (\%) & $3101(54.1)$ & $329(54.2)$ & 0.96 \\
\hline Weekly earnings, mean (SD) & $1212.4(2832.6)$ & $1001.4(659.4)$ & 0.23 \\
\hline Legal representation (yes), n (\%) & 1085 (18.9) & $370(61.0)$ & $<0.01$ \\
\hline Accident notification (days), mean (SD) & $22.6(22.9)$ & $23.9(21.4)$ & 0.32 \\
\hline Notification of claim (days), mean (SD) & $112.7(86.7)$ & $97.5(69.1)$ & $<0.01$ \\
\hline Rehabilitation indicator, $\mathrm{n}(\%)$ & & & $<0.01$ \\
\hline Required & $398(6.9)$ & $127(20.9)$ & \\
\hline Possibly required & $2920(50.9)$ & $287(47.3)$ & \\
\hline Not required & $1844(32.2)$ & $171(28.2)$ & \\
\hline Role & & & $<0.01$ \\
\hline Driver & $3764(65.6)$ & $386(63.6)$ & \\
\hline Passenger & $1120(19.5)$ & $156(25.7)$ & \\
\hline Rider & $404(7.0)$ & $23(3.8)$ & \\
\hline Pillion & $22(0.4)$ & $2(0.3)$ & \\
\hline Pedestrian & $237(4.1)$ & $30(4.9)$ & \\
\hline Cyclist & $159(2.8)$ & $7(1.2)$ & \\
\hline Other & $28(0.5)$ & $3(0.5)$ & \\
\hline Ambulance (yes) & $2179(38.0)$ & $300(49.4)$ & $<0.01$ \\
\hline
\end{tabular}


Table 1 Continued

\begin{tabular}{llcc}
\hline & Musculoskeletal injury & $\begin{array}{l}\text { Musculoskeletal } \\
\text { injury+psych distress }\end{array}$ \\
\hline Variable & $(\mathbf{n = 5 7 3 4 )}$ & $\mathbf{( n = 6 0 7 )}$ & $\mathbf{p}$ \\
\hline Hospital (yes) & $1405(24.5)$ & $173(28.5)$ & $<0.01$ \\
\hline
\end{tabular}

For some variables there were missing values; total number will therefore not always equal 6341 .

${ }^{*}$ At-fault claims are minor claims that are capped at payment of $\$ A 5000.00$.

\section{Claim settlement times, costs and legal representation}

ANOVA results confirmed a significant difference between musculoskeletal injury and musculoskeletal injury+psychological distress claim settlement times $(F=392.82$, $\mathrm{df}=1,6339, \mathrm{p}<0.001)$. Mean days to claim settlement from accident date was significantly longer for musculoskeletal injury+psychological distress compared with musculoskeletal injury only (353.81 days; SD=164.83; $95 \%$ CI 340.67 to 366.95 versus 231.65 days; $\mathrm{SD}=142.08 ; 95 \%$ CI 227.97 to 235.32 , respectively). This difference was significantly longer for musculoskeletal injury+psychological distress claimants (mean difference 122.16 days or 17.45 weeks).

ANOVA results also confirmed a significant difference in claim costs between musculoskeletal injury and musculoskeletal injury+psychological distress claimants $(F=444.03, \mathrm{df}=1,6339, \mathrm{p}<0.001)$. Mean claim costs for musculoskeletal injury only claimants was $\$ A 12421.13$; $\mathrm{SD}=370710.78 ; 95 \% \mathrm{CI} 11461.39$ to 13380.87 . Mean claim costs for musculoskeletal injury+psychological distress claimants was $\$ \mathrm{~A} 53996.52 ; \quad \mathrm{SD}=966930.42$; 95\% CI 46288.92 to 61704.11 . This is an overall mean increase of $\$ A 41575.39$ or 4.3 times more expensive per case. To understand better the effect of injury severity on claim costs, a further ANOVA was conducted with serious and above musculoskeletal injury removed. This did not change the findings. Mean cost for musculoskeletal injury was $\$ \mathrm{~A} 10034.54 \quad \mathrm{SD}=283780.90 ; 95 \% \mathrm{CI} 9267.37$ to 10801.71). Mean cost of musculoskeletal injury+psychological distress was $\$$ A43 262.87 ( $\mathrm{SD}=619270.97$; 95\% CI 38023.02 to 48502.71 ), and this was significantly greater for the musculoskeletal injury+psychological distress group $(F=516.71, \mathrm{df}=1,6607, \mathrm{p}=0.000)$. Musculoskeletal injury+psychological distress claimants were also significantly more likely $(\mathrm{p}<0.01)$ to involve legal representation $(61.0 \%$ compared with $18.9 \%)$.

\section{Impact of socio-demographic and injury characteristics on probability of psychological distress}

Table 1 presents the factors at the time of the MVC and claim lodgement that either increase or decrease the probabilities of musculoskeletal injury claimants being diagnosed with psychological distress. Age, economic loss (defined as yes/no) associated with the injury and claim, weekly earnings and hospitalisation did not

Table 2 Breakdown of musculoskeletal injury types by musculoskeletal injury versus musculoskeletal injury with psychological distress from 2011 to 2013

\begin{tabular}{lllr}
\hline Musculoskeletal Injury Type & $\begin{array}{l}\text { Musculoskeletal Injury Only (\%) } \\
\mathbf{n = 5 , 7 3 4}(\mathbf{9 0 . 4 3 \% )}\end{array}$ & $\begin{array}{l}\text { Musculoskeletal Injury + Psychological } \\
\text { Distress (\%) } \mathbf{n = 6 0 7}(\mathbf{9 . 5 7 \% )}\end{array}$ & Total \\
\hline Soft Tissue & $4630(89.78)$ & $527(10.21)$ & 5157 \\
Whiplash & $3750(89.43)$ & $443(10.56)$ & 4193 \\
\hline Skin & $2133(86.81)$ & $324(13.18)$ & 2457 \\
Lumbar & $1256(84.69)$ & $227(15.30)$ & 1483 \\
Chest & $985(86.10)$ & $159(13.89)$ & 1144 \\
Seatbelt & $672(84.31)$ & $125(15.68)$ & 797 \\
\hline Thoracic & $634(86.84)$ & $96(13.15)$ & 730 \\
Upper Limb Joint & $441(87.67)$ & $62(12.32)$ & 503 \\
\hline Upper Limb Fracture & $432(93.50)$ & $30(6.49)$ & 462 \\
\hline Lower Limb Fracture & $413(93.43)$ & $29(6.56)$ & 442 \\
Lower Limb Joint & $229(87.40)$ & $33(12.59)$ & 262 \\
\hline Face & $82(85.41)$ & $14(14.58)$ & 96 \\
Abdomen & $49(90.74)$ & $5(9.25)$ & 54 \\
Spinal Contusion & $2(100.00)$ & $0(0.00)$ & 2 \\
\hline Finger Amputation & $2(100.00)$ & $0(0.00)$ & 2 \\
\hline
\end{tabular}

Percentages in columns are row percentages showing the percentage of the total for each musculoskeletal injury type in the musculoskeletal distress only versus musculoskeletal+psychological distress categories. 
significantly increase the probability of psychological distress. Socio-economic disadvantage increased the probability of experiencing psychological distress (mean musculoskeletal injury 1017.9, SD=86.4; mean musculoskeletal injury+psychological distress $986.5, \mathrm{SD}=89.2$, $\mathrm{p}<0.01$ ). For example, over $40 \%$ of those with psychological distress were socially disadvantaged compared with $31 \%$ of those without psychological distress. There was a significant difference $(p<0.01)$ between male and female claimants in terms of probability of also having psychological distress; that is, $65.1 \%$ were female who had a musculoskeletal injury+psychological distress compared with $57.8 \%$ with only musculoskeletal injury. Claimants who were unemployed were more likely to have psychological distress $(\mathrm{p}<0.01)$ compared with those employed. A total of $4197(73.2 \%)$ of those working at the time of lodging their claim did not have psychological distress compared with $364(60.0 \%)$ of those with musculoskeletal injury+psychological distress. A total of $620(10.8 \%)$ of those with a history of a prior claim did not have psychological distress, whereas $86(14.2 \%)$ did have psychological distress, suggesting that those with a claim history are more likely to have psychological distress in addition to their musculoskeletal injury $(\mathrm{p}=0.01)$. Those with a musculoskeletal injury+psychological distress were more likely to have a serious injury severity score $(\mathrm{p}=0.02)$. Those with a musculoskeletal injury+psychological distress were also more likely to be not at fault (96.1\% compared with $87.9 \%$ for musculoskeletal injury only). It is noted here, however, that data taken from an 'at fault' scheme necessarily mean that there are limited at-fault claimants, reducing confidence in its association with psychological distress. No significant difference was found between the two groups in terms of number of days taken for notifying the insurer of the MVC (either via a minor claim, ie, Accident Notification Form, or a full claim). However, in terms of days taken to notify the insurer of the claim lodgement, those who had psychological distress were more likely to notify lodgement of their claim sooner $(\mathrm{p}<0.01)$. It was also more likely that the claimant will require rehabilitation if they have psychological distress $(p<0.01)$. A larger portion of passengers had psychological distress, whereas motorbike riders and cyclists were less likely to have psychological distress $(p<0.01)$. If an ambulance was required at the time of the MVC, the claimant was significantly more likely to have psychological distress in addition to their musculoskeletal injury $(\mathrm{p}<0.01)$, and similarly, if the claimant attended hospital, they were more likely to have psychological distress $(p<0.01)$ than if hospitalisation was not required.

\section{Logistic regression analysis of significant socio-demographic and injury characteristics}

All socio-demographic and injury characteristics that were found to significantly differentiate between the two groups were entered into a logistic regression to determine their unadjusted and adjusted predictive power of psychological distress. Table 3 shows that six variables were associated with the presence of psychological distress. Being unemployed, being female, being socio-economically disadvantaged, not being at fault, requiring an ambulance at the time of their MVC and needing rehabilitation were all found to be significant contributors to an increased risk of having psychological distress. The area under the ROC curve for this group of six variables was $70 \%$. Adding non-significant variables to the logistic regression did not significantly add to this percentage, providing validity for the predictive capacity of the model.

\section{Sensitivity analysis}

Sensitivity analysis was conducted with a subset of those that had PTSD only. In this subset, those with other types of psychological distress were excluded from the analysis. For those with PTSD diagnosis only $(n=83)$, SEIFA, fault and rehabilitation indicators were significant predictors. Although employment and sex were no longer significant in this model, the effect sizes for all predictors were greater in this PTSD-only subset, indicating that no significance is likely a result of reduced power in the sample. The overall performance of the model was greater in the PTSD-only subset with a concordance index of 0.764 compared with 0.695 in the original model.

\section{DISCUSSION}

In NSW, Australia, an MVC fault-based system is legislated that provides compensation for people injured in MVCs that were the fault of another vehicle owner or driver. The driver at fault is the person who was driving the vehicle considered most at fault in the accident. ${ }^{35}$ Analysis of the PIR data of all NSW compensation claimants over 27 months between 2011 and 2013 who met the inclusion criteria revealed that almost $10 \%$ of claimants will be diagnosed with elevated psychological distress such as depression or PTSD or a distressing condition involving significantly elevated anxiety and depressive mood. For comparison, the Australian prevalence of elevated psychological distress such as PTSD is estimated at $0.9 \% \pm 0.1 \%$ and depression is estimated at $3.5 \pm 0.2 \% 0 .{ }^{41}$ The prevalence of musculoskeletal injury with a comorbid depression has been estimated at $29.51 \pm 3.210 .{ }^{42}$ Furthermore, prior research has consistently found levels of psychologically distressing symptomatology to range between $20 \%$ and $40 \%$ for people sustaining injury in an MVC, irrespective of whether they have made a compensation claim. ${ }^{3}$ The current findings reported in this paper suggest a much lower percentage of psychological symptomatology. Nevertheless, the psychological data presented in this paper are reporting disorders rather than symptomatology. Distress associated with the claims process has been documented, ${ }^{3}$ and the significant escalations in time to claim settlement and cost increases revealed in this study warrant action for their amelioration. Prevalence differences found in prior studies may well be a factor of employing prospective research designs and research-based diagnostic assessments. However, the 
Table 3 Logistic regression results showing predictors for claimants who experience psychological distress

\begin{tabular}{|c|c|c|c|c|}
\hline Variable & $\begin{array}{l}\text { Unadjusted OR } \\
(95 \% \mathrm{Cl})\end{array}$ & $\mathbf{p}$ & $\begin{array}{l}\text { Adjusted OR } \\
(95 \% \mathrm{Cl})\end{array}$ & $\mathbf{p}$ \\
\hline Age & 1.01 (1.00 to 1.01 ) & 0.02 & & \\
\hline New Injury Severity Score & & 0.03 & & \\
\hline Minor-moderate 1-8 & 1.00 & & & \\
\hline Serious $9-15$ & 1.51 (1.12 to 2.04$)$ & 0.007 & & \\
\hline Severe-critical 16-75 & 1.20 (0.68 to 2.10$)$ & 0.53 & & \\
\hline Index of Relative Socioeconomic Disadvantage & & $<0.001$ & & $<0.001$ \\
\hline Most disadvantaged & 1.65 (1.28 to 2.12$)$ & $<0.001$ & 1.55 (1.18 to 20.6$)$ & 0.002 \\
\hline Disadvantaged & 0.83 (0.61 to 1.13$)$ & 0.24 & 0.87 (0.62 to 1.23$)$ & 0.43 \\
\hline Average & 1.00 & & 1.00 & \\
\hline Advantaged & 0.99 (0.74 to 1.32$)$ & 0.96 & 1.07 (0.77 to 1.48$)$ & 0.70 \\
\hline Most advantaged & 0.61 (0.47 to 0.79$)$ & $<0.001$ & $0.60(0.45$ to 0.81$)$ & 0.001 \\
\hline Male & 0.73 (0.62 to 0.87$)$ & $<0.001$ & 0.72 (0.59 to 0.88$)$ & 0.001 \\
\hline Employment status (yes) & 0.55 (0.46 to 0.65$)$ & $<0.001$ & 0.71 (0.58 to 0.87$)$ & 0.001 \\
\hline At fault (yes) & 0.29 (0.19 to 0.45$)$ & $<0.001$ & $0.25(0.15$ to 0.40$)$ & $<0.001$ \\
\hline Prior claim (yes) & 1.36 (1.07 to 1.73$)$ & 0.013 & & \\
\hline Rehabilitation indicator & & $<0.001$ & & $<0.001$ \\
\hline Required & 1.00 & & 1.00 & \\
\hline Possibly required & 0.31 (0.24 to 0.39 ) & $<0.001$ & $0.37(0.29)$ to 0.48$)$ & $<0.001$ \\
\hline Not required & 0.29 (0.23 to 0.38$)$ & $<0.001$ & $0.36(0.27$ to 0.48$)$ & $<0.001$ \\
\hline Other & 0.12 (0.08 to 0.19$)$ & $<0.001$ & 0.17 (0.08 to 0.38$)$ & $<0.001$ \\
\hline Role & & $<0.001$ & & \\
\hline Driver & 1.00 & & & \\
\hline Passenger & 1.36 (1.12 to 1.66$)$ & 0.002 & & \\
\hline Rider & 0.56 (0.36 to 0.86$)$ & 0.008 & & \\
\hline Pillion & 0.89 (0.21 to 3.78$)$ & 0.87 & & \\
\hline Pedestrian & 1.23 (0.83 to 1.83 ) & 0.30 & & \\
\hline Cyclist & 0.43 (0.32 to 3.45$)$ & 0.03 & & \\
\hline Other & 1.05 (0.32 to 3.45$)$ & 0.94 & & \\
\hline Transportation by ambulance (yes) & 1.47 (1.22 to 1.77$)$ & $<0.001$ & 1.44 (1.19 to 1.76$)$ & $<0.001$ \\
\hline \multirow[t]{2}{*}{ Hospital (yes) } & 1.14 (0.94 to 1.38$)$ & 0.19 & & \\
\hline & $\mathrm{ROC}=$ & 0.70 & & \\
\hline
\end{tabular}

p Values are shown.

current findings have considerable consequences given that they are based on outcomes from every MVC casualty in NSW over a 27-month period with a defined injury (musculoskeletal) and who settled their claim. Furthermore, the diagnosis of psychological distress was based on international mental health criteria (ICD-10-AM) and sourced from treating clinicians and independent medical/psychological assessments.

The findings also confirmed that the presence of psychological distress is associated with substantially increased claim settlement times, a mean increase of the total cost of the claim by over $\$ A 40000$. Legal representation was also significantly more likely in those with psychological distress. These findings provide compelling evidence, confirming that the presence of psychological distress during the claims process (regardless of whether it was premorbid or not) results in potentially adverse outcomes for the well-being of affected individuals and for insurance and regulatory organisations with increased settlement times and costs.

The identification of the factors that are likely to elevate risk of psychological distress during the claims process for injury compensation following an MVC provides healthcare professionals and insurance companies/regulatory bodies some scope for ameliorating the risk of escalating claim settlement times and costs. The current study provided evidence for six independent predictors of psychological distress during the claim process. It is 
not surprising that unemployment, social disadvantage and a history of prior claims are risk factors for increased psychological distress given that they are somewhat related factors and that prior research has indicated their contribution to poorer mental health status. ${ }^{43}{ }^{44}$ It is acknowledged that prior mental health problems can predispose people to elevated psychological distress after their MVC $;{ }^{39}$ however, there is no avenue available for assessing the impact of this influence given that such a predisposing factor is not routinely collected by insurance companies. Nevertheless, strategies and resources will need to consider this risk factor. Similarly, it is not surprising that being female is a risk factor for distress during the claims process given that higher prevalence rates of psychological distress for females are consistently reported across general populations. ${ }^{44}$ This would suggest that resources directed at females to prevent escalation of distress in the claims process appear warranted. Transportation by an ambulance at the time of their accident is perhaps related to severity of the injury, and future research will be needed to clarify this risk factor. Requiring rehabilitation was also found to be a significant predictor of psychological distress, perhaps suggesting that some claimants who become psychologically distressed may be receiving rehabilitation regardless of their physical injury severity. This suggests that early intervention for psychological distress may well reduce the need for extended rehabilitation. Similarly, resources directed at those who are not at fault of the MVC may help reduce the risk of psychological distress negatively impacting on the claim's expected settlement times and cost trajectories. For example, related to at-fault status, previous research has found a relationship between perceived injustice and the high prevalence of occupational disability in whiplash injuries. ${ }^{45}$ Changing to a no-fault scheme may reduce the association between fault status and increased claim settlement times and costs.

Limitations of this study need to be discussed. It was not possible to determine preinjury presence of psychological distress. It is expected that the presence of preinjury psychological distress would have a considerable impact on the presence of psychological distress during the claims process. However, arguably, proxy measures of preinjury psychological distress existed in the study, namely, social disadvantage and unemployment, both highly related to the presence of psychological disorder. ${ }^{43}$ These two measures were found to predict psychological distress during the claim process. Nevertheless, research with access to preinjury health data shows that diagnosed psychological/psychiatric illness prior to injury is a significant risk factor for psychological distress following an MVC incident. ${ }^{46}$ Due to the data being collected in a fault-based CTP scheme, very few claimants were at fault, and this may have been a factor in its predictor status of psychological distress. Clearly, the predictive capacity of fault status requires further research. The inclusion of only settled claims has the potential to exclude more claims in which psychological distress played a role given their propensity to be more lengthy for the claimant. It was also not possible to know with a high level of accuracy what psychological condition was experienced.

This retrospective cohort study has positive implications at several systemic levels. First, the results reported in this paper can assist general practitioners to provide improved healthcare support to their clients, knowing that those presenting with psychological distress in addition to their musculoskeletal injury may require additional support such as referral to a clinical psychologist or psychiatrist early in the claims process to reduce the risk of the claim becoming more complex and subsequently more lengthy and expensive. Second, assuming that the goal of insurance companies is to support a claimant through the process of compensation with effective injury management and timely return to work, the results presented suggest that there are known targets for change (psychological distress) and that specific predictors available in insurers' personal injury databases can effectively identify who is likely to benefit from specific distress management strategies. This suggests that changes to healthcare protocols and practices are warranted. For example, in accordance with previous research, directing additional resources such as screening and treating psychological conditions of claimants who are at higher risk ${ }^{9}$ regardless of whether their psychological condition predated their MVC provides opportunity for reducing time and costs involved with compensation claims.

Acknowledgements The authors acknowledge and thank the NSW MVC survivors whose data have been analysed and reported in this publication.

Contributors RG, YT and AC contributed to the study conception and design, analysis and interpretation of data, drafting of the manuscript and revision based on the comments of the co-authors. BG and IC contributed to the study design and revision based on comments of reviewers. All authors approved the submitted manuscript for publication.

Funding This research was funded by a competitive grant from the State Insurance Regulatory Authority (SIRA) (formerly the Motor Accident Authority NSW); MAA ref: $14 / 366$. The views expressed in this paper are those of the authors only and not those of SIRA's.

Competing interests None declared.

Provenance and peer review Not commissioned; externally peer reviewed.

Data sharing statement № additional data available.

Open Access This is an Open Access article distributed in accordance with the Creative Commons Attribution Non Commercial (CC BY-NC 4.0) license, which permits others to distribute, remix, adapt, build upon this work non-commercially, and license their derivative works on different terms, provided the original work is properly cited and the use is non-commercial. See: http://creativecommons.org/ licenses/by-nc/4.0/

(c) Article author(s) (or their employer(s) unless otherwise stated in the text of the article) 2017. All rights reserved. No commercial use is permitted unless otherwise expressly granted.

\section{REFERENCES}

1. Department of Transport. Reported road caualties in Great Britain: main resuts in 2014. 2015 www.gov.uk/government/uploads/system/ uploads/attachment_data/file/438040/reported-road-casualties-ingreat-britain-main-results-2014-release.pdf.

2. Bureau of Infrastructure, Transport, and Regional Economics (BITRE). Road trauma Australia, 2015 statistical summary BITRE. Canberra ACT, 2016. 
3. Craig A, Tran Y, Guest R, et al. Psychological impact of injuries sustained in motor vehicle crashes: systematic review and metaanalysis. BMJ Open. In Press. 2016;6:e011993.

4. Guest R, Tran Y, Gopinath B, et al. Prevention of the development of psychological distress following a motor vehicle crash: study protocol for a randomized controlled trial. Trials 2016;17:317.

5. Nantulya VM, Reich MR. The neglected epidemic: road traffic injuries in developing countries. BMJ 2002;324:1139-41.

6. Peden M. World report on road traffic injury prevention. Geneva: World Health Organization, 2004.

7. Heron-Delaney M, Kenardy J, Charlton E, et al. A systematic review of predictors of posttraumatic stress disorder (PTSD) for adult road traffic crash survivors. Injury 2013;44:1413-22.

8. Holbrook TL, Anderson JP, Sieber WJ, et al. Outcome after major trauma: 12-month and 18-month follow-up results from the Trauma Recovery Project. J Trauma 1999;46:765-73.

9. Papadakaki M, Ferraro OE, Orsi C, et al. Psychological distress and physical disability in patients sustaining severe injuries in road traffic crashes: results from a one-year cohort study from three European countries. Injury 2017;48:297-306.

10. Blanchard EB, Hickling EJ, Malta LS, et al. One- and two-year prospective follow-up of cognitive behavior therapy or supportive psychotherapy. Behav Res Ther 2004;42:745-59.

11. Grant GM, O'Donnell ML, Spittal MJ, et al. Relationship between stressfulness of claiming for injury compensation and longterm recovery: a prospective cohort study. JAMA Psychiatry 2014;71:446-53.

12. Elbers NA, Hulst L, Cuijpers $P$, et al. Do compensation processes impair mental health? A meta-analysis. Injury 2013;44:674-83.

13. Harris IA, Young JM, Jalaludin BB, et al. The effect of compensation on general health in patients sustaining fractures in motor vehicle trauma. J Orthop Trauma 2008;22:216-20.

14. Gabbe BJ, Cameron PA, Williamson OD, et al. The relationship between compensable status and long-term patient outcomes following orthopaedic trauma. Med J Aust 2007;187:14.

15. O'Donnell ML, Creamer MC, McFarlane AC, et al. Does access to compensation have an impact on recovery outcomes after injury? Med J Aust 2010;192:328-33.

16. Shuman DW. Psychology of Compensation in Tort Law, the. U Kan L $\operatorname{Rev}$ 1994:43:39.

17. Murgatroyd D, Lockwood K, Garth B, et al. The perceptions and experiences of people injured in motor vehicle crashes in a compensation scheme setting: a qualitative study. BMC Public Health 2015;15:423.

18. Chan AO, Medicine M, Air TM, et al. Posttraumatic stress disorder and its impact on the economic and health costs of motor vehicle accidents in South Australia. J Clin Psychiatry 2003;64:175-81.

19. Gabbe BJ, Simpson PM, Cameron PA, et al. Association between perception of fault for the crash and function, return to work and health status 1 year after road traffic injury: a registry-based cohort study. BMJ Open 2015;5:e009907.

20. Cassidy JD, Carroll LJ, Côté P, et al. Effect of eliminating compensation for pain and suffering on the outcome of insurance claims for whiplash injury. N Engl J Med 2000;342:1179-86.

21. World Health Organization. Global health risks: mortality and burden of disease attributable to selected major risks: World Health Organization. 2009.

22. Murray CJ, Atkinson $\mathrm{C}$, Bhalla $\mathrm{K}$, et al. The state of US health, 1990-2010: burden of diseases, injuries, and risk factors. JAMA 2013;310:591-608.

23. Littleton SM, Cameron ID, Poustie SJ, et al. The association of compensation on longer term health status for people with musculoskeletal injuries following road traffic crashes: emergency department inception cohort study. Injury 2011;42:927-33.

24. Giannoudis PV, Mehta SS, Tsiridis E. Incidence and outcome of whiplash injury after multiple trauma. Spine 2007;32:776-81.
25. Littleton SM, Cameron ID, Poustie SJ, et al. The association of compensation on longer term health status for people with musculoskeletal injuries following road traffic crashes: emergency department inception cohort study. Injury 2011;42:927-33.

26. Hendriks EJ, Scholten-Peeters GG, van der Windt DA, et al. Prognostic factors for poor recovery in acute whiplash patients. Pain 2005;114:408-16.

27. Sterling M, Kenardy J. Physical and psychological aspects of whiplash: important considerations for primary care assessment. Man Ther 2008;13:93-102.

28. Berglund A, Bodin L, Jensen I, et al. The influence of prognostic factors on neck pain intensity, disability, anxiety and depression over a 2-year period in subjects with acute whiplash injury. Pain 2006;125:244-56.

29. Carroll LJ, Cassidy JD, Côté P. The role of pain coping strategies in prognosis after whiplash injury: passive coping predicts slowed recovery. Pain 2006;124:18-26.

30. Sterling M, Kenardy J, Jull G, et al. The development of psychological changes following whiplash injury. Pain 2003;106:481-9.

31. Radanov BP, Begré S, Sturzenegger M, et al. Course of psychological variables in whiplash injury - a 2-year follow-up with age, gender and education pair-matched patients. Pain 1996;64:429-34.

32. Ameratunga SN, Norton RN, Bennett DA, et al. Risk of disability due to car crashes: a review of the literature and methodological issues. Injury 2004;35:1116-27.

33. Australian Consortium for Classification Development. $1998 \mathrm{https}: / /$ www.google.com.au/?gws_rd=ss|\#safe=off\&q=www.accd.net.au\% 2Ficd10.aspx.

34. State Insurance Regulatory Authority. Fees, Costs and Charges. 2015 http://www.sira.nsw.gov.au/motor-accidents/for-professionals/ fees-costs-and-charges.

35. Cutter A. Comparison across CTP schemes. Australasia: Institute of Actuaries of Australia, 2007.

36. Stevenson M, Segui-Gomez M, Lescohier I, et al. An overview of the injury severity score and the new injury severity score. Inj Prev 2001;7:10-13.

37. Pink B. Information paper: an introduction to Socio-Economic Indexes for Areas (SEIFA), 2006. Canberra: Australian Bureau of Statistics, 2008.

38. World Health Organization. The ICD-10 classification of mental and behavioural disorders: clinical descriptions and diagnostic guidelines. Geneva: World Health Organization, 1992.

39. Hosmer Jr DW, Lemeshow S. Applied logistic regression. John Wiley \& Sons, 2004.

40. Large MM. Relationship between compensation claims for psychiatric injury and severity of physical injuries from motor vehicle accidents. Med J Aust 2001:175:129-33.

41. Andrews G, Henderson S, Prevalence HW. Comorbidity, disability and service utilisation. Br J Psychiatry 2001:178:145-53.

42. Lloyd C, Waghorn G, McHugh C. Musculoskeletal disorders and comorbid depression: implications for practice. Aust Occup Ther J 2008;55:23-9.

43. Mezuk B, Rafferty JA, Kershaw KN, et al. Reconsidering the role of social disadvantage in physical and mental health: stressful life events, health behaviors, race, and depression. Am J Epidemiol 2010;172:1238-49.

44. Wilhelm K, Mitchell P, Slade T, et al. Prevalence and correlates of DSM-IV major depression in an Australian national survey. J Affect Disord 2003;75:155-62.

45. Sullivan MJL, Davidson N, Garfinkel B, et al. Perceived injustice is associated with heightened pain behavior and disability in individuals with whiplash Injuries. Psychol Inj Law 2009;2:238-47.

46. Ehlers A, Mayou RA, Bryant B. Psychological predictors of chronic posttraumatic stress disorder after motor vehicle accidents. $J$ Abnorm Psychol 1998;107:508-19. 